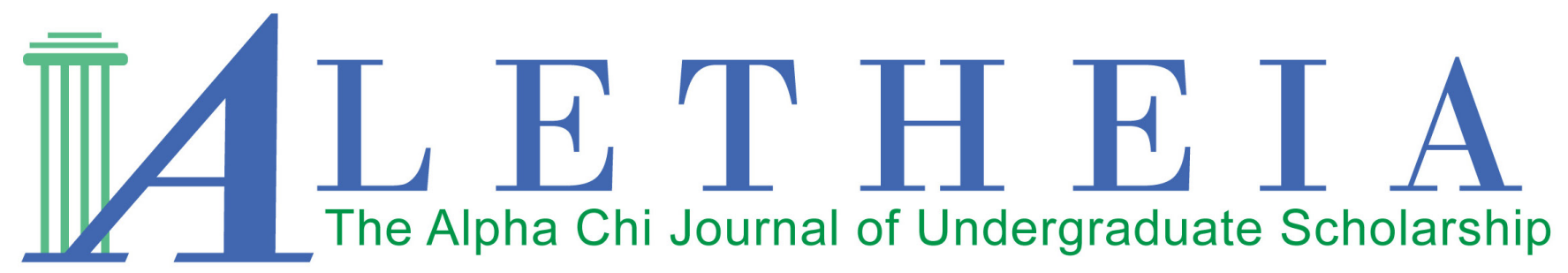

Volume 2 | Issue 2 | 2017

\title{
Small Mammal Survey and Census of Broad River Greenway and Surrounding Area, Boiling Springs, North Carolina, 2016
}

\author{
Christopher Lile
}

Gardner-Webb University

North Carolina Zeta Chapter

Vol. 2(2), 2017

Article Title: Small Mammal Survey and Census of Broad River Greenway and Surrounding Area, Boiling Springs, North Carolina, 2016

DOI: $10.21081 / \mathrm{AX} 0156$

ISSN: 2381-800X

Key Words: mammal, mark-recapture, trapping, survey

This work is licensed under a Creative Commons Attribution 4.0 International License.

Author contact information is available from the Editor at editor@alphachihonor.org.

\section{Aletheia-The Alpha Chi Journal of Undergraduate Scholarship}

- This publication is an online, peer-reviewed, interdisciplinary undergraduate journal, whose mission is to promote high quality research and scholarship among undergraduates by showcasing exemplary work.

- Submissions can be in any basic or applied field of study, including the physical and life sciences, the social sciences, the humanities, education, engineering, and the arts.

- Publication in Aletheia will recognize students who excel academically and foster mentor/mentee relationships between faculty and students.

- In keeping with the strong tradition of student involvement in all levels of Alpha Chi, the journal will also provide a forum for students to become actively involved in the writing, peer review, and publication process.

- More information and instructions for authors is available under the publications tab at www.AlphaChiHonor.org. Questions to the editor may be directed to editor@alphachihonor.org.

\footnotetext{
Alpha Chi is a national college honor society that admits students from all academic disciplines, with membership limited to the top 10 percent of an institution's juniors, seniors, and graduate students. Invitation to membership comes only through an institutional chapter. A college seeking a chapter must grant baccalaureate degrees and be regionally accredited. Some 300 chapters, located in almost every state, induct approximately 12,000 members annually. Alpha Chi members have been "making scholarship effective for good" since 1922.
} 
Volume 2 | Issue 2 | Fall 2017

Article Title: Small Mammal Survey and Census of Broad River Greenway and Surrounding Area,

Boiling Springs, North Carolina, 2016

DOI: $10.21081 / \mathrm{AX} 0156$

ISSN: 2381-800X

This work is licensed under a Creative Commons Attribution 4.0 International License.

\title{
Small Mammal Survey and Census of Broad River Greenway and Surrounding Area, Boiling Springs, North Carolina, 2016
}

\author{
Christopher Lile
}

\author{
Gardner-Webb University \\ North Carolina Zeta Chapter
}

\begin{abstract}
I conducted a small mammal survey at Broad River Greenway and Gardner-Webb University property from 23 May through 20 June, 2016. Six trapping sites were established, consisting of two shrublands, two forested areas, and two grasslands. I used a diamond-shaped grid system of trapping at each study site. The diamond was composed of five transects, each sixty meters long and starting twenty meters after the previous transect ended with a trap every twenty meters (for a total of 20 traps at each site). I used Sherman live traps of alternating sizes, each baited with a mix of commercial rodent food and rolled oats. Trapping sessions consisted of four consecutive nights for a total of 80 trap nights in each site (160 in each habitat and 480 trap nights for all sites combined). The following species were captured: Ochrotomys nuttalli (Golden Mouse); Peromyscus spp.; Sigmodon hispidus (Hispid Cotton Rat); and Sciurus carolinensis (Eastern Gray Squirrel). Trap success rate was $4.58 \%$ with the greatest capture recorded in the shrubland (5.88\%) and lower rates of capture in the forest $(3.97 \%)$ and grassland (3.87\%). Sigmodon hispidus were most abundant (42.86\%), while the Peromyscus spp. represented 38.1\% of captured individuals; the $O$. nuttalli and Sciurus carolinensis represented $14.29 \%$ and $4.76 \%$ respectively. Peromyscus spp. was the only species found in all habitat types, O. nuttalli was found in the forest and shrubland sites, and Sigmodon hispidus was found in the shrubland and grassland sites.
\end{abstract}

Key words: mammal, mark-recapture, trapping, survey

\section{Introduction}

Boiling Springs is a small rural town in western North Carolina and is home to Gardner-Webb University (GWU) and the Broad River Greenway (BRG), which consists of 607 ha of preserved land owned by Cleveland County and maintained by the Broad River Council. This work represents the first small mammal survey conducted in Boiling Springs, which establishes a baseline for future studies. Although Broad River Greenway is a preserved area, the surrounding private property experienced widespread deforestation from logging $100 \mathrm{~m}$ from the river bank, stretching approximately $0.8 \mathrm{~km}$. It is unknown what effect, if any, this has had on the species residing within the protected areas. It is crucial to have regular population surveys of small mammals for future wildlife conservation as rodents play a significant role in their ecosystems as a source as both food for predators and as seed dispersers (Hollander \& Vander Wall, 2004). These surveys are also important for studying disease prevention. Sigmodon hispidus and Peromyscus spp., both captured in the present study, are known carriers of hantaviruses (Mills et al., 1998). Although cases of infection are rare, the proximity of the study sites to human populations further emphasizes the importance of this survey and future research. The goal of this project was to generate a small mammal species inventory and calculate relative abundance of terrestrial small mammal species that reside in habitats within Broad River Greenway and the surrounding area. This research lays the groundwork for future small mammal research in this area. 


\section{Materials and Methods}

\section{Study Area}

The survey was conducted in three habitat types: forest, shrubland, and grassland. Two study plots were established in each habitat. Four trapping sites were established on University property and two trapping sites on Broad River Greenway property. The shrubland habitat on Gardner-Webb property, approximately $400 \mathrm{~m}$ from buildings and residential areas, was defined as a successional loblolly pine (Pinus taeda) plantation of 15 years, and was composed of dense undergrowth, including blackberry bushes (Rubus spp.) (Figure 1A). The shrubland study site on Broad River Greenway property was located approximately $800 \mathrm{~m}$ from the river. It was defined as a recovering old field successional forest following a fire and was composed of dense undergrowth, including blackberry bushes (Rubus spp.) (Figure 1B). The forest habitat on Gardner-Webb property, approximately $400 \mathrm{~m}$ from buildings and residential areas, was composed of lowland pine mixed hardwood with predominantly short leaf pine (Pinus echinata) (Figure. 1C). The forest study site on Broad River Greenway property was adjacent to the river and was composed of lowland mixed hardwood with predominantly sycamore trees (Platanus occidentalis) (Figure 1D). Parallel grassland habitat plots were sampled on Gardner-Webb University property several kilometers from the main campus, approximately $100 \mathrm{~m}$ from athletic facilities. Both grassland habitats were defined as successional grasslands leading to forest (Figures 1E \& F). The only notable difference between the grassland study sites was the presence of a small pond in the second grassland plot (Figure 1F).

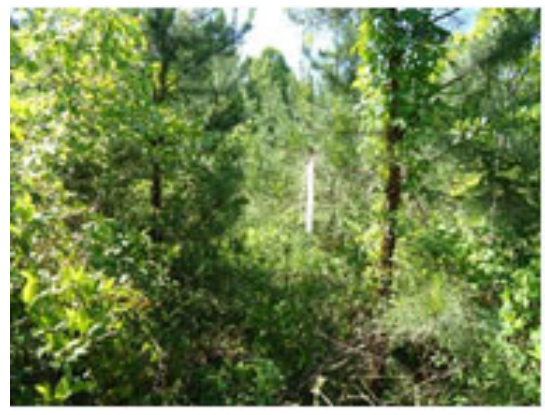

Figure 1A. GWU Shrubland

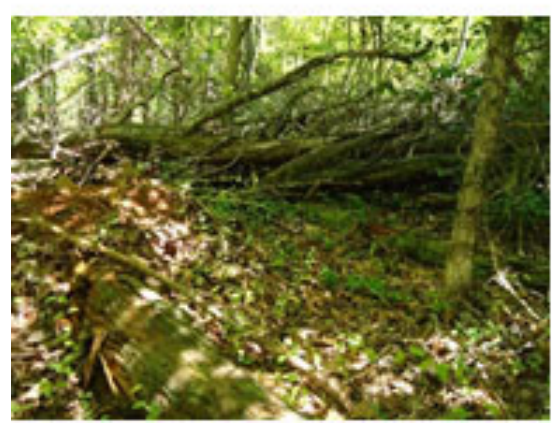

Figure 1D. BRG Forest

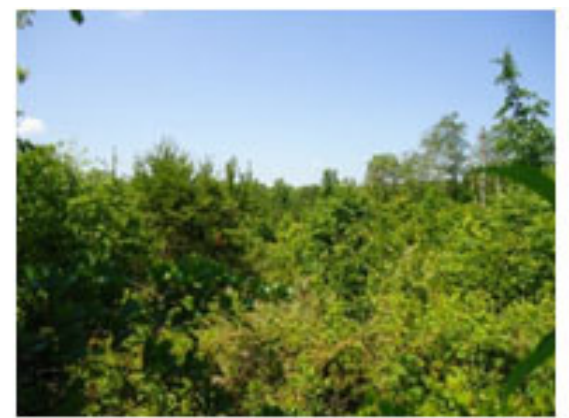

Figure 1B. BRG Shrubland

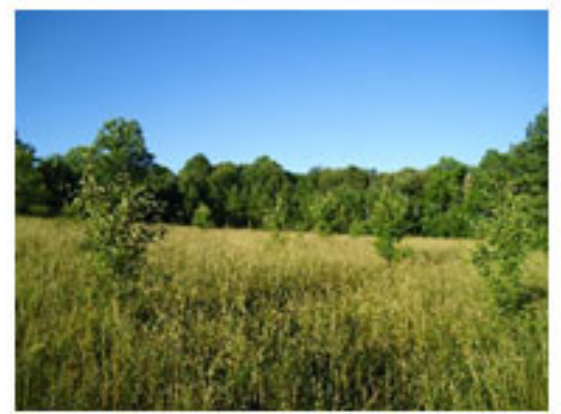

Figure 1E. GWU Grassland

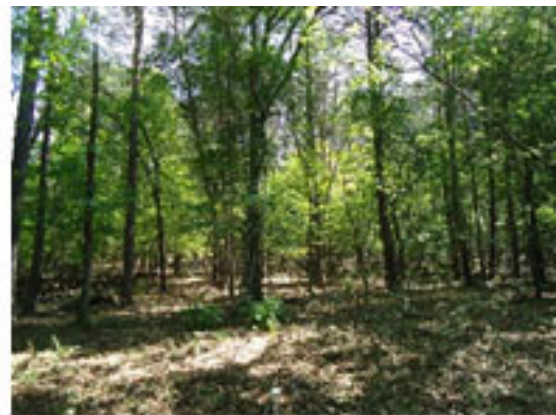

Figure 1C. GWU Forest

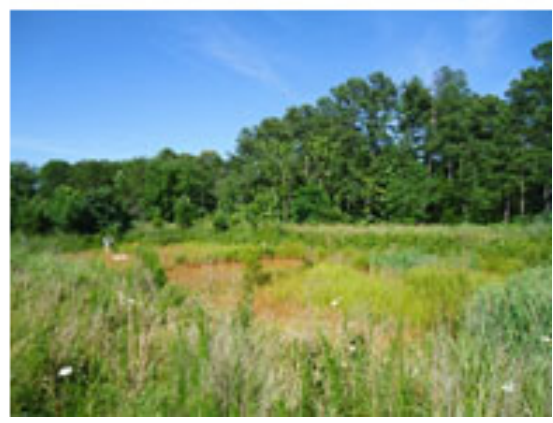

Figure 1F. GWU Grassland

Figures 1 A-F. Study sites established in Boiling Springs, NC. 


\section{Field Methods}

A diamond-shaped grid system of trapping was implemented for this study. The grid used in this study was designed to fit the size of the smallest sampled habitat (approximately $100 \mathrm{~m} \times 120 \mathrm{~m}$ ) and was used at each trapping location. The diamond was composed of five transects, each $60 \mathrm{~m}$ long and starting $20 \mathrm{~m}$ after the previous transect ended, with a trap every $20 \mathrm{~m}$ (Figure 2).

Trapping sessions consisted of one, four-night session, with traps set at dusk and checked at dawn. Twenty traps were set within each grid, totaling 80 trap nights at each location. Traps were placed within $2 \mathrm{~m}$ of the transect line in the closest sheltered area, such as underneath shrubbery or fallen trees. Sherman live traps, alternating sizes of 4" x 4-1/2" x 15" and 3" x 3-1/2" x 9 " to accommodate the range of size in small mammals, were used at each trapping site. The traps were baited at dusk with a mix of rolled oats and commercial pet rodent feed, including sunflower seeds and millet. An aromatic bait of peanut butter and rolled oats mix was initially used because trapping effectiveness is higher with aromatic bait (Oswald \& Flake, 1994). However, fire ants were attracted to each trap, so to prevent harm to the captured individuals, peanut butter was not used after the first trapping night in plot 1 (GWU shrubland). Fire ants were not found in traps when bait consisted of rolled oats and rodent feed. If heavy rains were forecasted during a trap night, traps were closed, and the night was not included as a trap night to prevent potential flooding of traps in low laying areas.

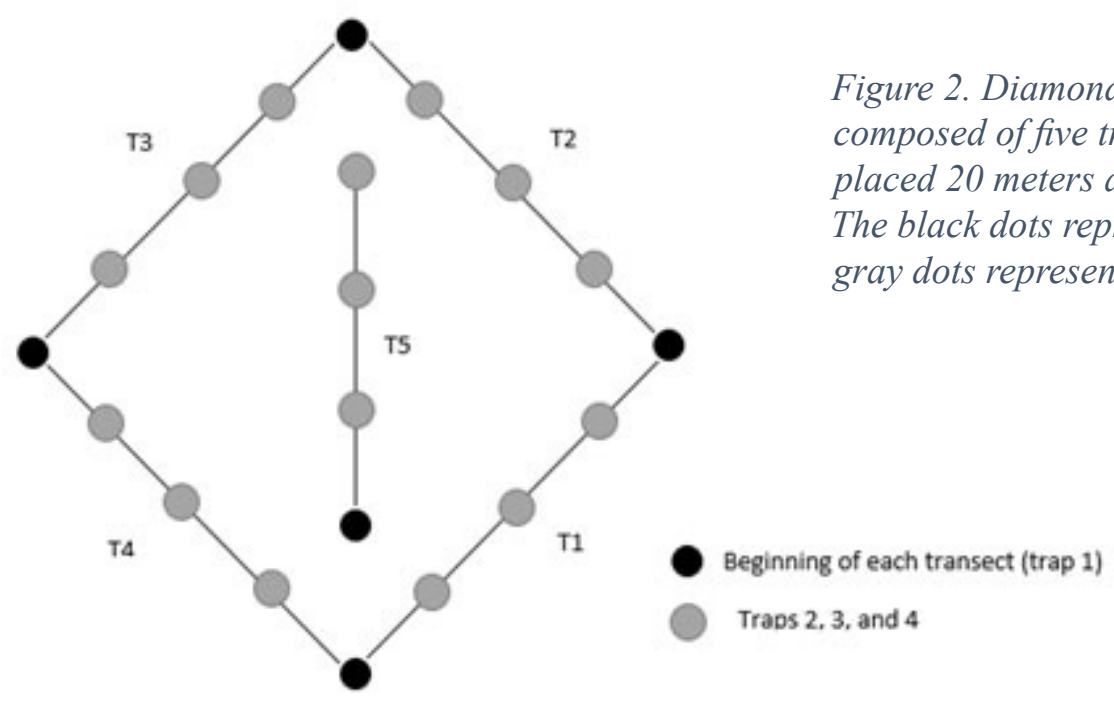

Captured animals were weighed, identified to species level, and examined to obtain information such as gender, body length, tail length, and reproductive status. The captured individuals were transferred from their trap into cloth bags to be weighed with a Pesola spring scale. No animals were kept as voucher specimens. Each animal was released after being photographed and marked on its foot or tail with non-toxic nail polish. Behavioral observations were recorded throughout the study.

These raw capture data were used for several calculations. Trap success for each habitat was found by dividing the number of captures by the number of trap nights in that habitat. The overall trap success was found by dividing the total number of captures by the total number of trap nights in the study. Effort was adjusted accordingly when individuals were recaptured or when larger mammals compromised data by triggering or damaging traps. Chi square was performed on these trap success data to compare small mammal captures between habitats. Species relative abundance was calculated for each species by dividing the total number of captured individuals by the number captured for each species. Habitat relative abundance was calculated by dividing the total number of captured individuals in each habitat type by the number of captured individuals of a particular species. Fisher's exact test was performed to compare differences in habitat relative abundance between the captured species. And finally, the Shannon Index of diversity was calculated for each habitat.

Figure 2. Diamond transect pattern. This pattern was composed of five transects $(T=$ transect $)$. Traps were placed 20 meters apart with four traps in each transect. The black dots represent trap 1 of the transects and the gray dots represent traps 2, 3 and 4. 


\section{Results}

The following species were captured during the survey: Ochrotomys nuttalli (Golden Mouse)

(Figure 3A); Peromyscus spp. (Figure 3B); Sigmodon hispidus (Hispid Cotton Rat) (Figure 3C) and Sciurus carolinensis (Eastern Gray Squirrel).

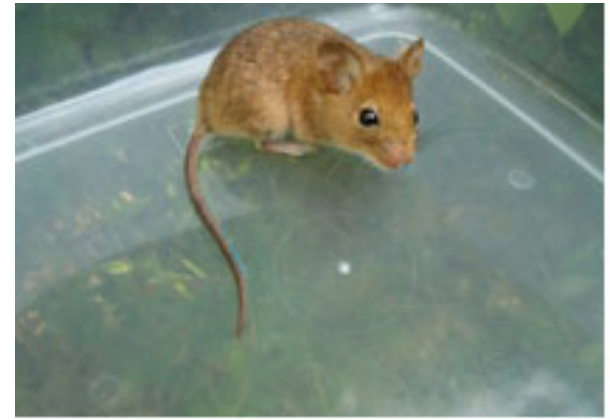

Figure $3 A$

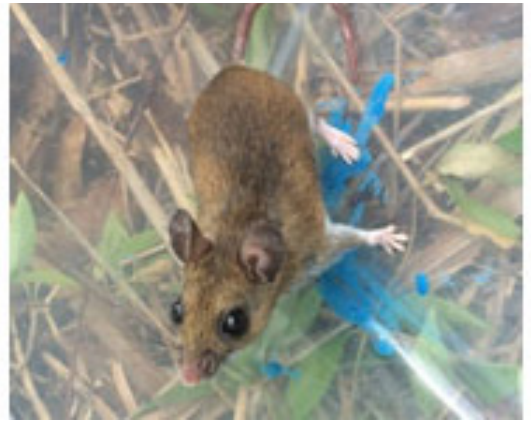

Figure 3B

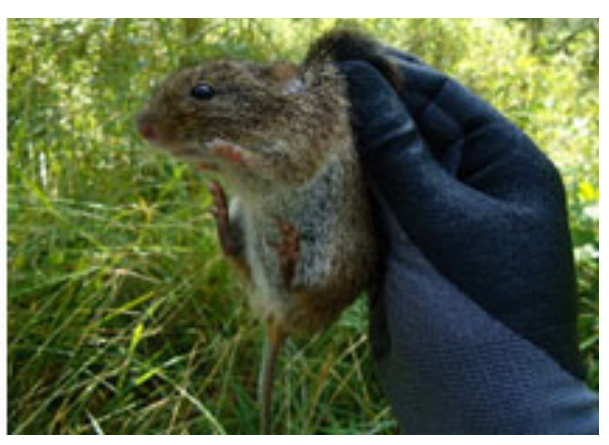

Figure $3 C$

Figures 3 A-C: Species captured in this survey. O. nuttalli (Figure 3A), Peromyscus spp. (Figure 3B), Sigmodon hispidus (Figure 3C), and Sciurus carolinensis (not pictured).

\section{Trap Success Rate}

Trap success rates represent the percentage of captures from the traps in each habitat (Figure 4). From a total of 80 trap nights at each site (160 for each habitat and 480 trap nights for all sites combined), nine individuals were captured in the shrubland habitats, and six individuals were captured in both the forest and grassland habitats. Effort was adjusted in each habitat for recaptured individuals and compromised traps. Traps were closed for only three nights during this study due to heavy rains. Overall trap success was $4.58 \%$, with the highest success in the shrubland (5.88\%) and lower trap success in the forest (3.97\%) and grassland habitats (3.87\%). However, analyses revealed no significant differences among the small mammal captures between the shrubland, forest, and grassland habitats $\left(\chi^{2}=0.86, \mathrm{df}=2\right.$, $\mathrm{p}>0.05$ ).

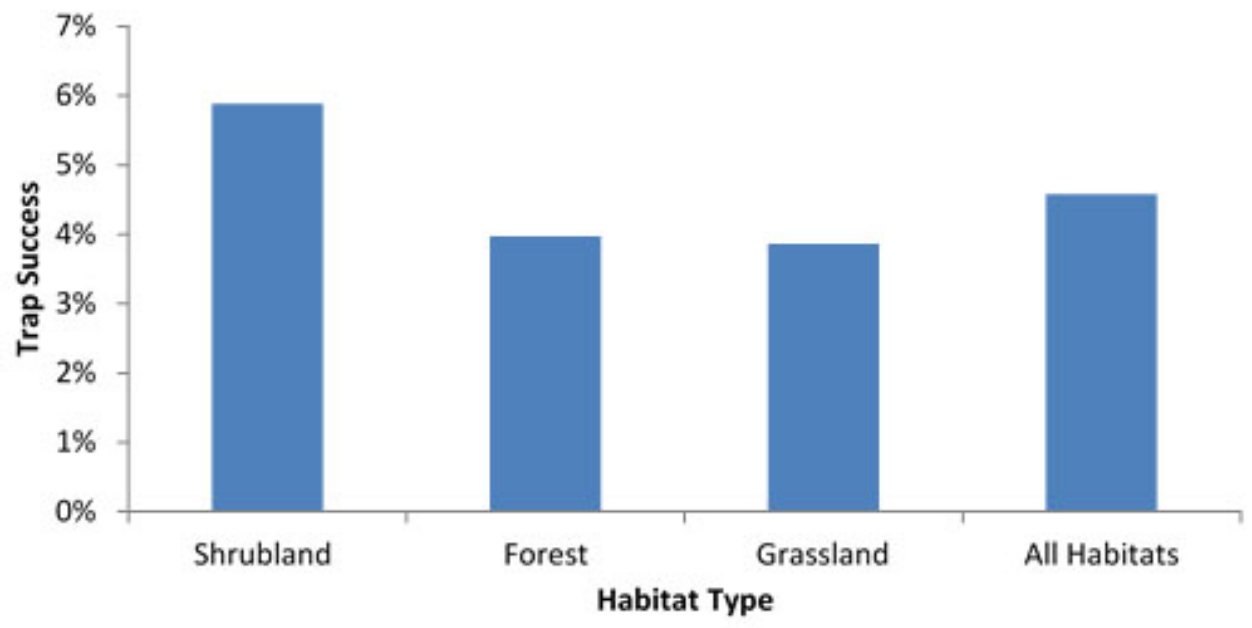

Figure 4. Trap Success in each habitat type. This represents the percentage of captures from the traps in each habitat. 


\section{Species Relative Abundance and Diversity}

Species-relative abundance represents the percentages of each species captured across all habitats (Figure 5). Sigmodon hispidus was most abundant (42.86\%), while Peromyscus spp. represented $38.1 \%$ of captured individuals, and the $O$. nuttalli and Sciurus carolinesis represented $14.29 \%$ and $4.76 \%$ respectively.

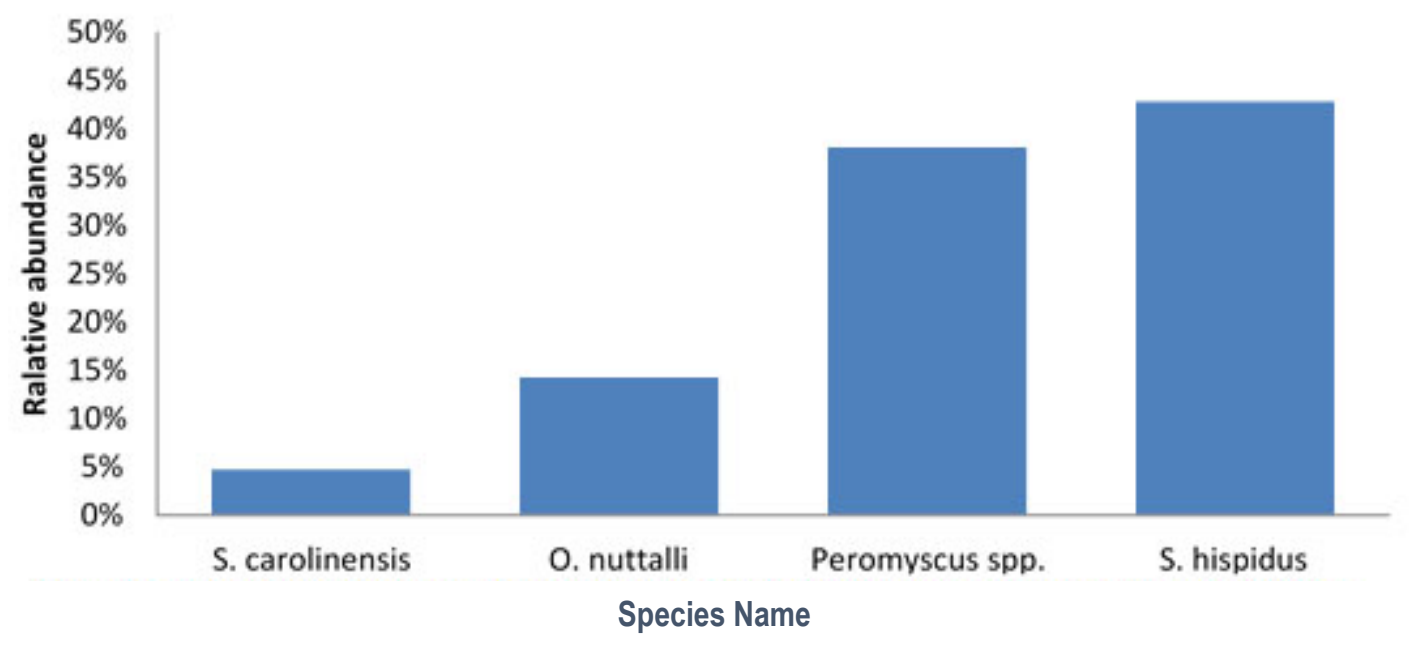

Figure 5. Species relative abundance across habitats. Each species is shown as a percentage of individuals captured across all habitat types.

\section{Habitat Relative Abundance}

Habitat relative abundance represents the percentage of each species captured within each habitat type (Fig. 6). Sigmodon carolinensis represented $16.67 \%$ of individuals captured in the forest habitats. Ochrotomys nuttalli represented $11.11 \%$ of individuals captured in the shrubland habitat and $33.33 \%$ in the forest habitat. Peromyscus spp. was the only species captured in each habitat type, representing $33.33 \%$ of all captured individuals in the shrubland habitat, $50 \%$ in the forest habitat, and $33.33 \%$ in the grassland habitat. Sigmodon hispidus represented $55.56 \%$ of individuals captured in the shrubland habitat and $66.67 \%$ in the grassland habitat. In habitats where they were caught, Sigmodon hispidus represented the highest percentages of captured individuals, and Peromyscus spp. represented the highest percentage of individuals captured in the forest habitat. However, these differences in habitat relative abundance among the species were not statistically significant ( $\mathrm{P}=0.131$, Fisher's exact test).

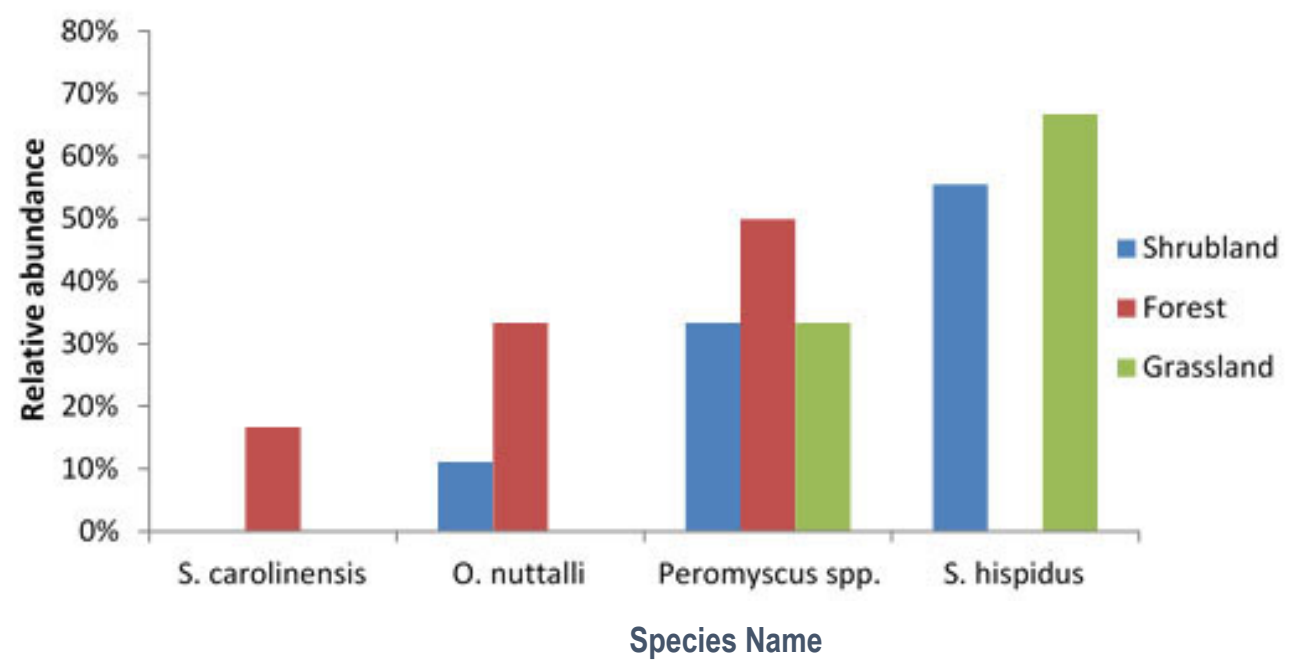

Figure 6. Habitat relative abundance. This represents the distribution of species within each habitat. 


\section{Shannon Index of Diversity}

The Shannon Index of Diversity for all habitats was calculated at 1.153 . For the shrubland habitat, the value was calculated at 0.937 ; the forest habitat was calculated at 1.011 , and the grassland habitat at 0.693 .

\section{Discussion}

It is known that there are many more small mammal species in Boiling Springs, NC than detected through this study (T. Jones, personal communication, May 2016). The present survey detected four of the mammal species residing in this area. This is a lower number than expected but comprises the first small mammal survey of Broad River Greenway and the surrounding areas. None of the species captured in this survey are threatened or endangered.

Although the habitats did not yield equal trap success, analyses revealed no significant differences among small mammal captures between habitats $\left(\chi^{2}=0.86, \mathrm{df}=2\right.$, $\mathrm{p}>0.05)$. Overall trap success was low $(4.58 \%)$, similar to other small mammal surveys yielding success lower than 5\% (Ordóñez-Garza et al., 2014; Engilis et al., 2012; Ragai \& Tuen, 2006). No preference was detected between trap size and body size of captured individuals. The shrubland yielded the greatest number of captures. This can be attributed to three species being captured in this habitat, with a particularly high number of Sigmodon hispidus. This species was captured in similar numbers in the grasslands, but only one other species was detected in this habitat. Sigmodon hispidus are most frequently captured in dense, grass dominated habitats, explaining the high rates of capture in the shrubland and grassland study sites (Cameron \& Spencer, 1981).

The survey was dominated by Sigmodon hispidus and Peromyscus spp., representing $42.86 \%$ and $38.1 \%$ of the captured individuals, respectively. However, Peromyscus spp. was found evenly across all habitats, while Sigmodon hispidus was found only in the shrubland and grassland habitats. Peromyscus spp. can survive in a wide range of habitats and are highly adaptable (Lackey et al., 1985). Ochrotomys nuttalli was only found within the study sites on Broad River Greenway, which were thicker and contained taller, more densely populated trees than the study sites on university property. This species has been noticed to prefer areas with moist thickets and forests, and generally uses early and mid-successional habitats (Morzillo et al., 2003).
Although these distinctions were recorded among habitats, mammal relative abundance did not differ among habitats $(\mathrm{P}=0.131$, Fisher's exact test). This result could be attributed to low trap success rate in each habitat. The Shannon Index of Diversity showed the highest diversity in the forest habitats and the lowest diversity in the grassland habitats. Although the forests and shrublands both yielded three species in each habitat, there was more evenness among the captured species in the forest, resulting in a higher value of diversity (Smith \& Smith, 2015). The grassland habitat was the least diverse with only two species, possibly because of the close proximity to residential buildings and sports facility.

There were several limitations to this study. The trapping grid was limited to twenty traps in each plot due to small habitats that ended abruptly or transitioned into different habitat- types. Limited resources restricted the study to Sherman Live Traps, potentially limiting the number of captured species in this research. For example, shrews were likely present in the study sites, but these species often require pitfall traps for successful capture. In addition, aromatic bait, such as peanut butter and bananas, could not be used because fire ant populations compromised the safety of captured mammals.

This research generated the first species list and data on species composition between habitats of small terrestrial mammals at Broad River Greenway and the surrounding area. The necessity of regular population surveys for conservation purposes signifies the importance of this research. 


\section{Acknowledgements}

This project was funded by Gardner-Webb's Summer Scholars research program. Special thanks to Dr. June Hobbs for coordinating the funds for this project and lending support. And thanks to the Undergraduate Research Advisory Board for granting the opportunity and commodities to pursue this research.

This research would not have been possible without a $\$ 300$ research stipend from the North Carolina Independent Colleges and Universities (NCICU), which was used to purchase Sherman Live traps.

A huge thanks to Dr. Joseph Oyugi for assisting in the development and completion of this project and for the constant advice and a helping hand. His enthusiasm and support helped make this project enjoyable and successful.

Special thanks to Dr. Tom Jones for the valuable advice, the assistance in identifying species, and the habitat descriptions.

Special thanks to Dr. Ed Pivorun and Dr. Patrick Brannon for help in the description of Peromyscus.

\section{References}

Cameron GN, Spencer SR. (1981). Sigmodon hispidus. Mammalian Species. 158,1-9

Crossland JP, Dewey, MJ, Barlow, SC, Vrana,PB, Felder, MR, \& Szalai, GJ. (2014). Caring for Peromyscus spp. in research environments. Lab Animal, 43(5) (2014):16-166.

Engilis, A, Cole, RE, \& Caro, TM. (2012). Small mammal survey of Chiquibul forest reserve, Maya mountains, Belize, 2001. Mus of Tex Tech Univ.,308,1-24.

Hollander, JL \& Vander Wall, SB. (2004). Effectiveness of six species of rodents as dispersers of singleleaf pinon pine (Pinus monophylla). Oecologia,138(1) (2004):57-65.

Lackey, JA, Huckaby, DG, \& Orminston, BG. (1985). Peromyscus leucopus. Mammalian Species, 247,1-10

Linzey, DW \& Packard, RL. (1977). Ochrotomys nuttalli. Mammalian Species, 75,1-6.

Mills JN, Johnson, JM, Ksiazek, TG, Ellis, BA, Rollin, PE, Yates, TL, Mann, MO, Johnson, MR, Campbell, ML, Miyashiro, J, \& Patrick, M. (1998). A survey of hantavirus antibody in small-mammal populations in selected United States National Parks. The Am Journal of Tropical Medicine and Hygiene, 58(4) (1998):525-532.

Morzillo, AT, Feldhamer, GA \&Nicholson, MC. (2003). Home range and nest use of the golden mouse (Ochrotomys nuttalli) in southern Illinois. J of Mammalogy, 84(2) (2003):553-560.

Ordóñez-Garza, N, Matson, JO, Eckerlin, RP, Bulmer, W \& Greiman, SE. (2014). Small mammal community from an isolated, remnant cloud forest in Guatemala. Mus of Tex Tech Univ, 324,1-12.
Oswald, CD, Flake, LD. (1994). Bait formulation effectiveness in live-trapping small mammals in eastern South Dakota, Proc of the South Dakota Academy of Science: 73,101-108.

Ragai, R \& Tuen, A. (2006). A Small Mammal Survey Within the Planted Forest Zone, Bintulu, Sarawak. Regional Conference of Biodiversity Conservation in Tropical Planted Forests in Southeast Asia [Internet]. [retrieved 20 May 2016]. Available from: http://ir.unimas.my/id/ eprint/7048

Smith, TM \&Smith, RL. (2015). Elements of ecology. Hoboken, NJ: Pearson Education Inc., p. 337 


\section{Appendix}

\section{Species Accounts}

\author{
ORDER RODENTIA \\ Family Cricetidae \\ Ochrotomys nuttalli (Harlan, 1832) \\ Golden Mouse
}

Three individuals (one male and two females) were captured. This species was only found within the shrubland and forest habitats of Broad River Greenway. The male was captured in the Broad River Greenway shrubland on trapping night three. The females were captured in the Broad River Greenway forest. One female, a reproductive adult, was captured on trapping night two and recaptured in a trap 60 meters from the original on trapping night four. This was the only individual recaptured farther than twenty meters from the original trap. The other female, a juvenile, was captured on trapping nights three and four in the same trap. These mice are known to share nests with up to eight individuals (Linzey \& Packard, 1977), suggesting that a significant population of $O$. nuttalli may reside in the areas surrounding the trapped individuals. This species is semi arboreal (Linzey \& Packard, 1977) and both females were observed climbing trees after being released, though no arboreal nests were spotted.

\section{Peromyscus spp. (Gloger, 1841)}

Eight individuals (four females and four males) were captured. Most individuals of this species were recaptured at least once. Three individuals were found in shrublands, three in forests, and two in grasslands. This species was found in each study site, with the exception of plot three, a grassland. Three individuals were noted as reproductive adults; two females were lactating, and one male had scrotal testes. Several individuals were noticed drumming their paws, a fear response common to species in the genus Peromyscus when experiencing threatening situations (Crossland et al., 2014). Half of the captured individuals possessed a bi-colored tail, a trait of Peromyscus maniculatus (North American Deer Mice). However, based on the elevation and lack of fur on the tips of their tails, these individuals could also be considered Perommyscus leucopus (White Footed
Mice). But because of the plastic characteristics of the Peromyscus genus, the captured individuals in this study were referred to as Peromyscus spp.

\section{Sigmodon hispidus (Say \& Ord, 1825) Hispid Cotton Rat}

Nine individuals (seven females and two males) were captured, with only two recaptures. Sigmodon hispidus was the most abundant species in the survey. Five individuals were captured in the GWU shrubland, while the other four individuals were captured in the grassland study sites. Three individuals, the two males and one of the females, were juvenile. Two adult females gave birth to litters while in the trap: one litter of five, and one litter of seven. The litters were placed in shaded, sheltered areas near the trap in the hopes that the dams would return for them. One dam was recaptured in the same trap the day after giving birth.

\section{Family Sciuridae Sciurus carolinensis (Gmelin, 1788) Eastern Gray Squirrel}

One individual was captured in the forest plot located on Gardner-Webb University property. This species was not intended to fit in the traps set within this study site and was, therefore, difficult to remove. After removal, the individual was released as we did not have suitable equipment for the measurement and weighing of larger mammals. 